\title{
THE SCIENCE EXPERIMENT AND THE PLAYFUL LEARNING: WINDOW OF OPPORTUNITY FOR CURRICULAR ARTICULATION IN THE TRANSITION BETWEEN PRESCHOOL EDUCATION AND PRIMARY EDUCATION
}

\author{
D. Alveirinho ${ }^{1}$, J. Bento ${ }^{2}$, M. Nunes ${ }^{3}$ \\ ${ }^{1}$ Higher School of Education - Polytechnic Institute of Castelo Branco (PORTUGAL) \\ ${ }^{2}$ Agrupamento de Escolas Gardunha e Xisto, Fundão (PORTUGAL) \\ ${ }^{3}$ Agrupamento de Escolas Afonso de Paiva, Castelo Branco (PORTUGAL)
}

\begin{abstract}
This article presents the reflexive analysis of a strategy of science teaching through the inquiry-based science education, of curricular articulation between pre-school education and the primary school education, within the framework of in-service training of teachers. The main objectives of this training course titled "The science experiment and the playful learning", were: to develop procedural skills to implement playfulness activities oriented to the action and participation of the students with intentionality to learn science; to develop knowledge and procedural skills in the experimental problem solving in science; and to operationalize practical activities that promote a smooth transition of the students between the different educational cycles.

The subjects that have been developed in this study are included in the curriculum of the kindergarten and the primary school, which involved interdisciplinary aspects between science, mathematics, arts and portuguese, as light and colour, primary and secondary colours, volumes and capacities measurements and colour saturation. It was applied scientific vocabulary, predicting, experimental procedures, and analysis of the results. In addition, the friendship, the sharing, the trust and the respect were also explored. The project was evaluated through the analysis of content of field notes, observation grids and the satisfaction evaluation in the final of the activities, as well as the reflexive analysis of the educators and teachers involved.
\end{abstract}

Keywords: Science experiment, playful learning, curricular articulation, preschool education, primary education, in-service training of teachers.

\section{INTRODUCTION}

Experiment in science, by providing learning from an interdisciplinary perspective, allows us to understand the world as a whole [1]. The inquiry-based science education provides to children the capacity to work in group, with mutual respect and tolerance, as well as skills and attitudes inherent in the science education [2]. Experiment in science through constructivist learning leads to the acquisition and development of a scientific literacy that involves skills, attitudes and values that contribute to the formation of citizens capable of dealing with everyday scientific aspects [3, 4].

The scientific community recognizes the importance of playfulness activity as essential to the growth and development of human kind, but that cannot be seen only as entertainment. Playfulness provides a voluntary and pleasant behaviour, facilitating the socialization process, knowledge construction, and can be applied, appropriately, in various age groups $[5,6,7]$. Playfulness used as a strategy in the science experimentation, is an excellent opportunity to provide environments that facilitate learning in science and the integral development of students.

Because of its potential to develop interdisciplinarity, the activities that apply science experiment can be an effective way of articulating different methodologies, contents, skills and attitudes. Thus, it is a precious strategy that facilitates the curricular approximation between the different levels of education, enabling the creation of spaces for exchange between different levels of education, so that the transitions between them become more harmonious to the students and promote the sequentially of the teaching and learning process $[8,9]$.

The in-service training of teachers that integrates preschool and primary teachers reveals a favourable context for the meeting, discussion and reflection of curricular articulation of science education 
integrated in other areas of knowledge, as well as putting into practice activities of curricular articulation in the transition between the different levels of education.

\section{METHODOLOGY}

In the present study, we used an action-research methodology line, since this work enabled teachers to participate in processes of reflection in the action and on the action of their educational practice to promote change in their teaching practices in regard to science education.

The study was developed with 28 children, 12 of five years old of preschool and 16 of nine years old, attending the 4th year of a Primary School that belongs of a Group of Schools in a town in Portugal, two teachers of the 1st Cycle of Basic Education (primary school) and one kindergarten teacher.

The main objectives of the study were: (a) to develop the scientific spirit in the children, equipping them with experimental skills for solving problems; (b) to provide children of the kindergarten and 4th year students of the 1st Cycle of Basic Education (primary school) the opportunity to work in a collaborative dynamic; (c) to reinforce in the teachers, procedural skills to implement playful activities, with the intention of their students learning science.

Implementation took place during three mornings, in the classroom of the students of the 4th year of schooling. Twelve pairs, consisting of children of both levels, were formed to provide collaborative and mutual aid work. One of the 4th graders was responsible for recording the spontaneous ideas and opinions of the pre-school children.

The study involved the implementation of a teaching strategy around the theme "Exploring the colours", having been subdivided into three parts: (a) "Colour mixing"; (b) "Reversibility of colours" and (c) "Properties of colour: saturation".

This theme was chosen because it involves a wide range of diversity of important concepts, allowing the experimental exploration through problem solving, interdisciplinarity and playfulness, besides being a theme that fits both in the kindergarten curriculum and in the 4th year of Basic Education.

Three cycles of experimenting with inquiry-based learning took place, bearing in mind that the answer to a problem question led to the formulation of a new problem question.

The implementation of the strategy began with the motivation using the short story "Little Blue and Little Yellow" [10] read orally by the 4th grade students, for preschool children. The exploration of the tale made it possible to introduce the words "colour", "light", and "blend of colours "," friendship "," sharing "," trust" and "respect".

It also enabled the identification of children's conceptions regarding the theme. The children were led to formulate their first problem question "What will happen when Little Blue and Little Yellow hug each other?"

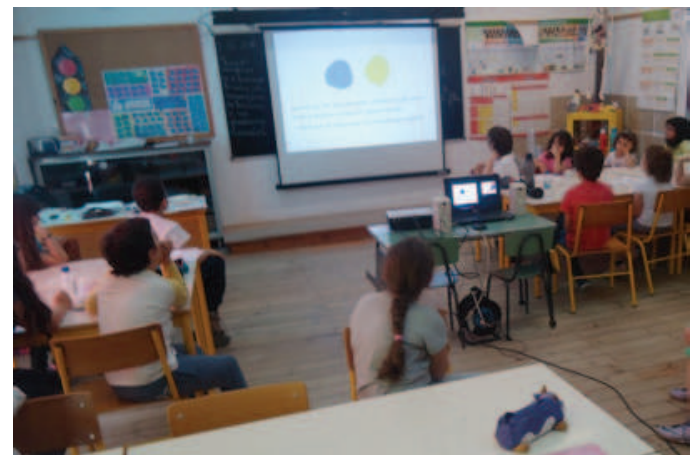

Figure 1 - Student reading "Little Blue and Little Yellow" [10].

When the students identified the problem, the question was formulated and the students proceeded to perform an experimental activity to verify what happens when two different primary colours are mixed.

Students formulated predictions, manipulated the material, controlled and manipulated variables, collect and analyse results, verify that the predictions are correct or not, concluded and answered the 
problem question. The 4th year students wrote all the records and helped preschool children. In this activity, for instance, coloured ice cubes were placed in a yellow liquid solution.

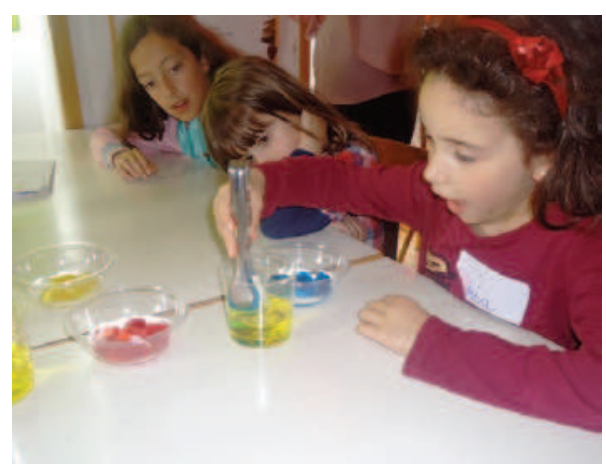

Figure 2. Students placing coloured ice cubes in a yellow liquid solution.

In continuity, we gave each pair of students a set of three coloured balloons symbolizing the colours that had been mixed.

As an application students used the Paint software, having verified the resulting colours when overlapping primary colour circles. With this activity all preschool children understood that without light there is no colour, and that the sunlight is white. To finish this activity, kindergarten children sang the song "The Colours" and 4th year graders recited the poetry "The Colour".

At the end of the first activity (first learning cycle) and to start the second activity (second learning cycle): "Reversibility of colours". Kindergarten children returned to the school of the 4th year students and were organized in the same dynamic, in pairs. The story of "Little Blue and Little Yellow" [10] continued to be presented. Now that "Little Blue has turned into a Little Green, how can he be blue again to be recognized by his parents?"

This issue triggered the second problem question: "Can secondary (and/or tertiary) colours be separated?". As a motivation, revision of the formation of secondary colours and to test the functionality of various materials, it was decided to use plasticine. Children chose two pieces of primary colour plasticine and they kneaded and shaped it until they obtained the resulting secondary colour.

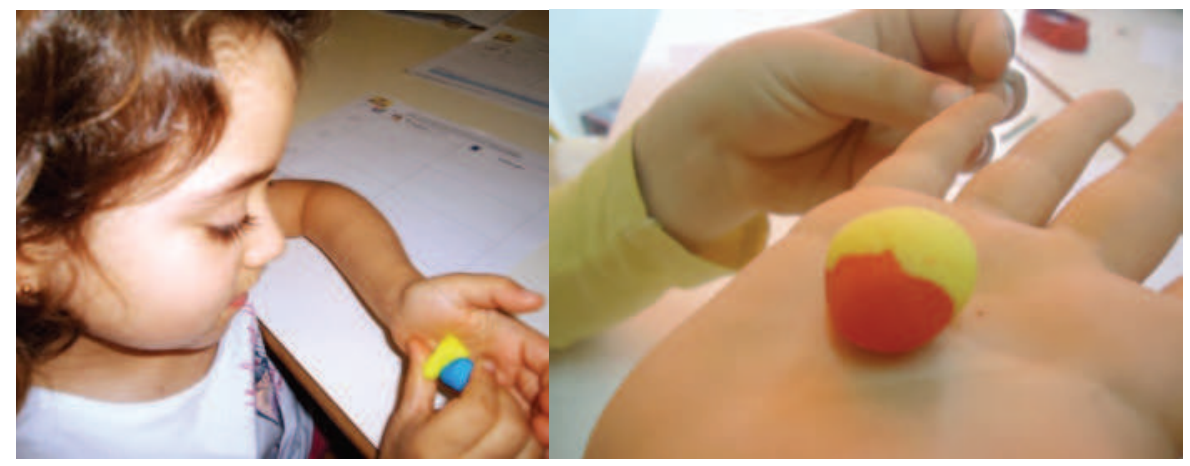

Figure 3. Children get secondary colours by kneading plasticine.

Children were asked if it would be possible to return the initial pieces of plasticine. After verifying that the plasticine is a material that does not allow the reversibility of colours, this question was oriented to the aspect of attitudes: we must think before acting, because in life there are options that we take that do not allow us to go back. And they realized that if "Little Blue and Little Yellow were made of plasticine, they would turn green forever!"

After the children mentioned other coloured materials for our experimental activity, we chose the felt pens. So, just as the "Little Blue" and the "Little Yellow" are hidden in the "Little Green", are there also hidden colours in the felt pens and can we separate them to see them? With the participation of the 4th year students we formulated the second question: "Can secondary and tertiary colours be separated in primary colours?" 
The enthusiasm for the problem-question was evident. Virtually every child would like to know to where the colours that gave rise to green went and whether it was possible to go back to the original colours. Then the students went on to perform the second experimental activity: paper chromatography using felt pens.

Once again, students formulated predictions, manipulated the material, controlled variables, checked predictions, recorded the results, completed, and answered the problem question. They noticed that the colours of the felt-tip pens separated and the children again looked at the primary colours. Which was a surprise to the children.

At the end of this collaborative work, the 4th grade students, through the technique of paper chromatography, elaborated coloured circles that turned into flowers that they placed in small pots to offer to the preschool children. In this way, the sharing and collaboration among children continued to be valued.

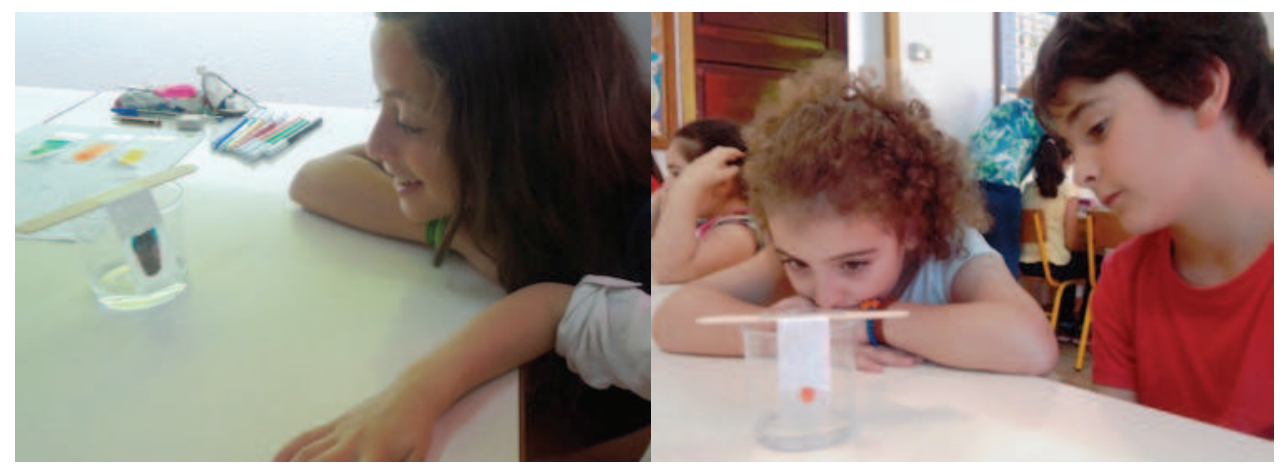

Figure 4. Children observe the reversibility of secondary and tertiary colours.

During the third morning, now only with the 4th year students and in their classroom. Teachers intended to explore the concept of colour saturation, one of the three properties that characterize it.

Teachers reminded students of the diversity of concepts already studied on colour. Students formulated the third problem question: "Does the saturation value of a colour change its tone?". To study this concept involved interdisciplinarity between the areas of experimental science, mathematics, arts and Portuguese. The use of mathematics was essential. Students measured volumes and capacities, calculated triple of the volume of white gouache and doubled the volume of black gouache and handled syringes (without needles) of different capacities and eyedropper.

Students developed the third cycle of inquiry-based learning "Properties of colour: saturation", around the concept of saturation of colours green, blue, yellow and red. Students, controlling variables, proceeded to colour saturation, adding amounts of white or black, in increasing order.

Students have realized that if the saturation value of a colour varies, its tone does not change, only the saturation is different. They also understood that the more white or black you add to a colour, the less saturation it will be. They concluded that saturation shows how a colour is pure or intense. The students created a saturation matrix.

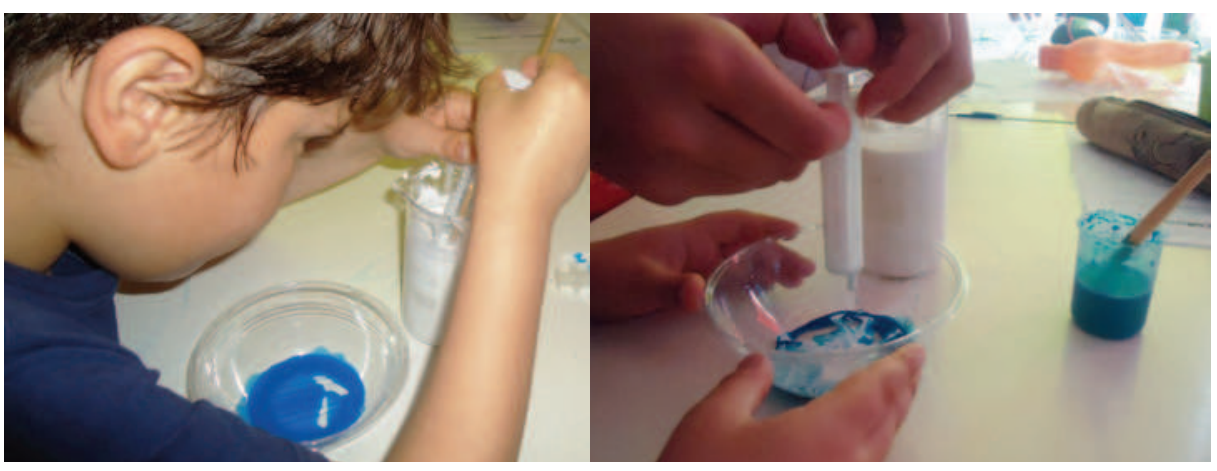

Figure 5. Children use syringes to create the colour saturation matrix. 
To finish the implementation of the strategy, a screen was distributed to each group and, giving colour to their creativity, the students applied the gradation of colour saturation in a monochromatic painting.

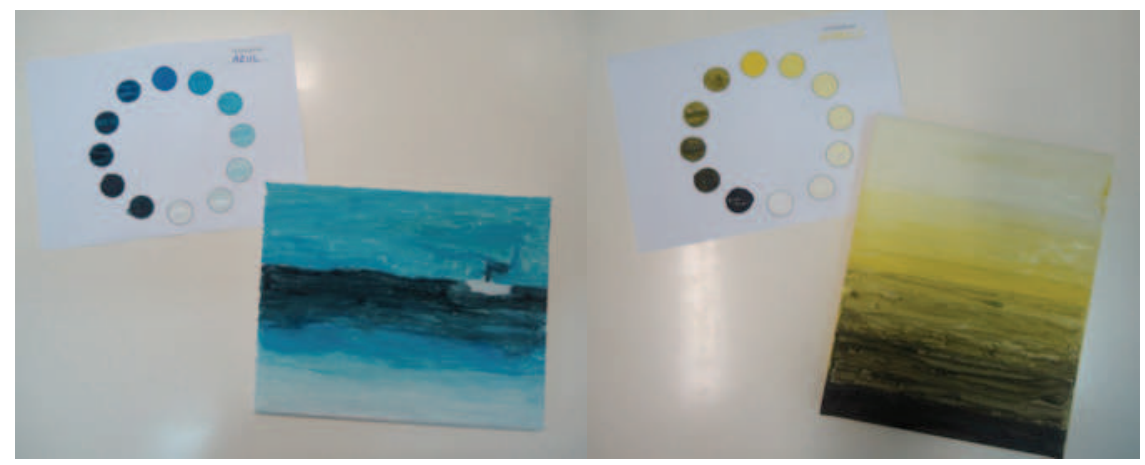

Figure 6. Saturation of colours: monochromatic paintings painted by students.

\section{RESULTS}

From the content analysis of the individual reflective report of the teacher who attended the training action and developed this strategy, the observation grids and the field notes, we registered the following results.

With regard to the first learning cycle, "Exploring colours ... mixing colours", from the analysis of the conceptions of the children it was noticed that the majority of the preschool children had some difficulty in verbally realizing their thinking.

The introduction of the light/colour concept was very interesting because this notion for the children initially was not internalized and most of them thought that the colours came from the rainbow or that someone had done magic to make the world more colourful and beautiful.

In the records of the 4th year students, it was found that most of them had the notion, more or less consolidated, about the colour blending. The illustrative application in Paint software made it possible to observe the analogies that the children made quite easily, using the colour mixture in computer support.

It is important to highlight the work of 4 th year students, by the way they helped the little ones, by the responsible attitude throughout the activity, fulfilling with enthusiasm and dedication what they had been asked for. It was found to be an enriching personal and social experience for all involved.

As for the second learning cycle, "Reversibility of colours", the stare and attentive to the colours that separated from the colour painted with the felt-tip pen, showed the interest and the commitment to the discovery.

Through the records of the predictions, most children thought that the gray colour of the felt-tip pen was black and white, and on the black felt there was only black. But the discovery that surprised most was the decomposition of gray, black and brown. Some children also sought to decompose the primary colours as a way of verifying that they were only composed of a single colour.

In addition to the importance of articulation between the different levels, interdisciplinarity was emphasized, involving different curricular areas, in a motivational and playful perspective, consolidating knowledge and developing transversal skills.

With regard to the third learning cycle, "Properties of colour: saturation", it was verified that the students internalized the procedures effectively. If they initially followed the teacher's instructions, later each group performed the experimental activity at their own pace, sharing the tasks, registering and showing a remarkable capacity for autonomy.

It was gratifying to see the ease with which the children internalized the experimental process.

The handling of the syringes (without needles) and the eyedroppers was quite amusing, assuming, in practical terms and measurements, a very suitable and functional material. 
This activity was extremely positive and rewarding for the potentialities it promoted at the level of knowledge, interdisciplinarity, interest and commitment of students, allowing critical, scientific and collaborative development.

The learning achieved met the expectations of the teachers, believing to have provided the playful experiences, but mainly, rigorous procedures in the scope of problem solving in the experimental sciences.

The curricular articulation between the two levels of education, despite having taken some time, proved to be an interesting process with benefits both for the kindergarten group and for the 1st cycle students group. Both groups registered a high degree of satisfaction for the collaborative work that took place.

With regard to teachers, they have recognized experimentation in science, employing a practical and playful approach, as an interdisciplinary and of peers work strategy, which promote in their students learning in Science.

Teachers reflected on the change of practices in a school context and assumed that the teaching of the experimental sciences and the playful one can be a window of opportunity for the curricular articulation in the transition between the preschool education and the primary school education.

\section{CONCLUSIONS}

The accomplishment of this study in the scope of the participation in this action of continuous training teachers allowed the reinforcement of procedural competences, as well as the enrichment and updating of knowledge.

It was very important the contact with different perspectives of approach in the practical and experimental teaching of the sciences. The students' implementation of pedagogical, scientific-playful and interdisciplinary pedagogical practices enable effective learning of know, know-now and knowhow of the students.

The promotion of collaborative and curricular work among pre-primary and 1st Cycle of Basic Education (primary school) children has contributed to the demystification of primary school activities among pre-school children.

It also contributed to increase students' self-esteem, as they felt fulfilled by helping pre-school children to carry out their activities. The enthusiasm and interests revealed and the consequent reflections contributed to the personal, social and scientific growth of all those involved.

The planning of experimental activities and the implementation of experimental situations allowed students to internalize the rigor of science. What should guide the day to day life.

It was considered essential to "give voice" to children and involve them in scientific attitudes, namely in the development of curiosity, the spirit of openness and cooperation, respect for evidence, critical reflection and perseverance.

This problem-solving methodology has contributed to being more attentive to these attitudes, to experimental rigor, to the various stages of the learning cycle, in order to develop children's thinking, at the level of conceptions, predictions, experimentation, comparison and the formulation of answers.

We conclude that this teaching methodology of the experimental sciences, articulated in an interdisciplinary way and sprinkled with playfulness, is a work that throughout the year can be made possible allowing students to learn the topics of the curriculum.

The planned activities have made us reflect on the methodologies used in the past and the present and certainly contributed to being more attentive and being more rigorous in future practices. Combining playfulness with the experimental sciences stimulates interest for the discovery in our students.

\section{ACKNOWLEDGEMENTS}

We would like to express our sincere thanks to the collaboration of the kindergarten teacher, to her availability and understanding, to the 12 children in her class as well as to the 16 primary school students, for their joy, enthusiasm and motivation, without which this study would not have been viable. 


\section{REFERENCES}

[1] I. Martins, M.L. Veiga, F. Teixeira, C. Tenreiro-Vieira, R.M. Vieira, A.V. Rodrigues, and F. Couceiro, Educação em Ciências e Ensino Experimental - Formação de Professores. Lisboa: Ministério da Educação - Direç̧ão-Geral de Inovação e Desenvolvimento Curricular, 2007.

[2] J. Barell, Problem-based Learning: An Inquiry Approach. Thousand Oaks, CA: Corwin Press, 2007.

[3] M. Rocard, P. Csermely, D. Jorde, D. Lenzen, H. Walberg-Henriksson, and V. Hemmo, Science Education Now: A Renewed Pedagogy for the Future of Europe. Brussels: European Commission - High Level Group on Science Education, 2007.

[4] M.L. Bentley, E.S. Ebert, and C. Ebert, Teaching Constructivist Science K-8. Thousand Oaks, CA: Corwin Press, 2007.

[5] L.S. Vygotsky, A Formação Social da Mente. São Paulo: Martins Fontes, 2007.

[6] J. Piaget, A Formação do Símbolo na Criança. Rio de Janeiro: Ed. Zahar, 1978.

[7] A.G. Silva, Aprendizagem por Meio da Ludicidade. Rio de Janeiro: Sprint, 2005.

[8] C. Serra, Currículo na Educação Pré-Escolar e Articulação com o $1^{\circ} \mathrm{CEB}$. Porto, Portugal: Porto Editora, 2004.

[9] M.C. Roldão, A Articulação Curricular - do Pré-Escolar ao $2^{\circ}$ Ciclo da Educação Básica. Lisboa: Ministério da Educação, 2009.

[10] L. Lionni, Pequeno Azul e Pequeno Amarelo. Matosinhos, Portugal: Kalandraka, 2010. 